\title{
Induction of cell proliferation and survival genes by estradiol-repressed microRNAs in breast cancer cells
}

Xinfeng Yu ${ }^{1 *}$, Xuemei Zhang ${ }^{2}$, Ishwori B Dhakal ${ }^{3}$, Marjorie Beggs ${ }^{3}$, Susan Kadlubar ${ }^{3}$ and Dali Luo ${ }^{1}$

\begin{abstract}
Background: In estrogen responsive MCF-7 cells, estradiol $\left(E_{2}\right)$ binding to ERo leads to transcriptional regulation of genes involved in the control of cell proliferation and survival. MicroRNAs (miRNAs) have emerged as key posttranscriptional regulators of gene expression. The aim of this study was to explore whether miRNAs were involved in hormonally regulated expression of estrogen responsive genes.

Methods: Western blot and QPCR were used to determine the expression of estrogen responsive genes and miRNAs respectively. Target gene expression regulated by miRNAs was validated by luciferase reporter assays and transfection of miRNA mimics or inhibitors. Cell proliferation was evaluated by MTS assay.

Results: $E_{2}$ significantly induced bcl-2, cyclin D1 and survivin expression by suppressing the levels of a panel of miRNAs (miR-16, miR-143, miR-203) in MCF-7 cells. MiRNA transfection and luciferase assay confirmed that bcl-2 was regulated by miR-16 and miR-143, cyclinD1 was modulated by miR-16. Importantly, survivin was found to be targeted by miR-16, miR-143, miR-203. The regulatory effect of $E_{2}$ can be either abrogated by anti-estrogen ICI 182, 780 and raloxifene pretreatment, or impaired by $E R \alpha$ siRNA, indicating the regulation is dependent on ERo. In order to investigate the functional significance of these miRNAs in estrogen responsive cells, miRNAs mimics were transfected into MCF-7 cells. It revealed that overexpression of these miRNAs significantly inhibited $\mathrm{E}_{2}$-induced cell proliferation. Further study of the expression of the miRNAs indicated that miR-16, miR-143 and miR-203 were highly expressed in triple positive breast cancer tissues, suggesting a potential tumor suppressing effect of these miRNAs in ER positive breast cancer.

Conclusions: These results demonstrate that $E_{2}$ induces bcl-2, cyclin D1 and survivin by orchestrating the coordinate downregulation of a panel of miRNAs. In turn, the miRNAs manifest growth suppressive effects and control cell proliferation in response to $E_{2}$. This sheds a new insight into the integral post-transcriptional regulation of cell proliferation and survival genes by miRNAs, a potential therapeutic option for breast cancer.
\end{abstract}

\section{Background}

$17-\beta$-estradiol $\left(E_{2}\right)$ regulates genes directly by binding to estrogen receptors (ERs) that are ligand-activated transcription factors and indirectly by activating plasma membrane-associated ERs which, in turn, activates intracellular signaling cascades leading to altered gene expression [1]. Therefore, ERs may participate in both the genomic (transcriptional) and non-genomic actions of $E_{2}$ [2]. $E_{2}$-liganded ERs interacts directly with a

\footnotetext{
* Correspondence: xinfengyu@hotmail.com

'Department of Pharmacology, School of Chemical Biology \& Pharmaceutical

Sciences, Capital Medical University, 100069, Beijing, China

Full list of author information is available at the end of the article
}

specific DNA sequence called the estrogen response element (ERE = 5'-AGGTCAnnnTGACCT-3') located in the promoter region of target genes [3]. DNA bound ERs then recruits transcriptional coregulators or interacts with other transcription factors, such as AP-1[4] and $\mathrm{Sp}-1$ [5] to indirectly modulate target gene transcription.

To date, two isoforms of the ERs ( $\alpha$ and $\beta$ ) have been identified which are able to bind to DNA as homo- or heterodimers. However, it has been shown that, in MCF-7 cells, ER $\alpha$ represents the predominant form, while ER $\beta$ is barely detectable [6]. Most studies so far have focused on $E_{2}-E R \alpha$ mediated transcriptional 
regulation of genes involved in the control of cell proliferation and survival. It has been reported that $E_{2}$ upregulates the bcl- 2 mRNA level in MCF-7 cells via two EREs located within the coding region [7]. The expression of cyclin D1, a gene involved in G1 phase cell cycle progression, is induced by $E_{2}$ in human breast cancer cells. Further studies have identified multiple enhancer elements involved in this regulation [8-11]. $\mathrm{E}_{2}$ also induces survivin upregulation as shown by a gene expression profiling analysis [12]. In hormone-responsive human breast cancer cells, ligand-activated ER $\alpha$ regulates target gene transcription by binding to their DNA response elements (EREs) or by tethering to other trans-acting factors $[13,14]$. However, the effect of $E_{2}$ on gene expression at the post-transcriptional level still needs further investigation.

MicroRNAs (miRNAs) are a class of evolutionarily conserved small, non-coding RNAs that control gene expression at the post-transcriptional level [15]. They regulate gene expression by base pairing to the 3'UTR of target mRNA, resulting in direct cleavage and/or translation inhibition of the target mRNA $[16,17]$. Several studies on miRNA array analysis in MCF-7 cells have demonstrated that $\mathrm{E}_{2}$ regulates a variety of miRNAs. $E_{2}$ upregulates 21 miRNAs and downregulated 7 miRNAs in MCF-7 vector control stable cells treated with $E_{2}$ for $4 \mathrm{~h}$ [18]. $\mathrm{E}_{2}$ downregulates the expression of mature miRNAs and pre-miRNAs (miR-195, miR-125a, miR-143, miR-145, miR-16, miR-190), but not pri-miRNAs in both mice and cells [19]. Maillot et al. [20] have shown the expression of a broad set of miRNAs (miR181a, miR-21, miR-26a, miR-200c, miR-27b, miR-23b) decreases following $E_{2}$ treatment in an ER-dependent manner. Based on previous microRNA expression profilings, we demonstrated that miR-16, miR-143 and miR203 were potentially suppressed in response to $E_{2}$ treatment in MCF-7 cells by QPCR quantification. Recently, estradiol-regulated miRNAs have been reported to control estrogen response and cell growth in breast cancer cells $[18,20]$. However, whether these estradiol-repressible miRNAs coordinately control cell proliferation and survival by targeting bcl-2, cyclin D1 and survivin at the post-transcriptional level in breast cancer cells is not fully investigated.

In the present study, we demonstrated that $\mathrm{E}_{2}$ significantly induced bcl-2, cyclin D1 and survivin expression by suppressing the expression of a set of miRNAs in ER $\alpha$ dependent manner in MCF-7 cells. The downregulated miRNAs exhibited the growth suppressive effect in response to $E_{2}$ and were highly expressed in triple positive breast cancer tissues. The study revealed the posttranscriptional regulation of estradiol-induced cell proliferation and survival genes by coordinately suppressing a panel of miRNAs, which may serve as therapeutic options in breast cancer treatment.

\section{Methods \\ Cells and treatment}

$17 \beta$-estradiol, raloxifene, fulvestrant (ICI 182, 780) were purchased from Sigma (Sigma, St. Louis, MO). The breast cancer cells MCF-7, MDA-MB-231 were obtained from the American Type Culture Collection (ATCC, Rockville, MD) and were maintained at $37^{\circ} \mathrm{C}$ under $5 \%$ $\mathrm{CO}_{2}$. MCF-7 cells were maintained in IMEM medium supplemented with $10 \%$ fetal bovine serum (FBS) and $0.01 \mathrm{mg} / \mathrm{ml}$ bovine insulin (Invitrogen, Carlsbad, CA). MDA-MB-231 were maintained in DMEM medium with $10 \%$ FBS. Prior to ligand treatment, cells were incubated with phenol red-free IMEM supplemented with 5\% charcoal stripped FBS for $48 \mathrm{~h}$ (serum-starved). Then cells were treated with ethanol (vehicle control, $0.01 \%$ final volume), $10 \mathrm{nM} \mathrm{E} \mathrm{E}_{2}$ for each time course or pretreated with $1 \mu \mathrm{M}$ ICI 182, 780 or raloxifene respectively for $6 \mathrm{~h}$, then treated in combination with $10 \mathrm{nM} \mathrm{E}_{2}$ for $48 \mathrm{~h}$.

\section{Western blot}

Cells were harvested and whole cell extracts were prepared in modified RIPA buffer and separated by $4-12 \%$ NuPAGE Bis-Tris gel electrophoresis (Invitrogen, Carlsbad, CA). Proteins were transferred onto PVDF membrane and probed with anti-cyclin D1, anti-bcl-2 (Santa Cruz Biotechnology, Santa Cruz, CA), anti-survivin (R\&D systems, Minneapolis, MN) antibodies at $4^{\circ} \mathrm{C}$ overnight, then the membrane was incubated with secondary antibody for $1 \mathrm{~h}$ before chemiluminescence detection using Pierce ECL Western Blotting Substrate (Pierce, Rockford, IL). $\beta$-actin was also detected as a loading control using mouse monoclonal antibody (Sigma, St. Louis, MO).

\section{Transfection of siRNA and miRNA}

MiR-16, miR-143, miR-203 mimics and inhibitors were purchased from Ambion and transfected into cells with lipofectamine 2000 (Invitrogen, Carlsbad, CA). The final concentration of miR-16, miR-143, miR-203 mimics and inhibitors was $40 \mathrm{nM}$. After $48 \mathrm{~h}$, cells were harvested and bcl-2, cyclin D1 and survivin expression were measured. A nonspecific miRNA mimic or inhibitor was used as negative control.

ER $\alpha$ siRNA was purchased from Dharmacon SMARTpool siRNA, MCF-7 cells were transfected with $100 \mathrm{nM}$ ER $\alpha$ siRNA for $24 \mathrm{~h}$ using lipofectamine 2000, then stimulated with $10 \mathrm{nM} \mathrm{E}_{2}$ for $24 \mathrm{~h}$ and $48 \mathrm{~h}$.

\section{Real-time quantitative PCR (QPCR)}

For detection of miRNA expression, miScript Reverse Transcription Kit (Qiagen, Valencia, CA) was used for 
cDNA synthesis. miScript SYBR Green PCR Kit (Qiagen, Valencia, CA), in combination with a pair of miRNA specific primers were used for mature miRNA detection. RNU6B was used as an internal control. Taqman probes and gene specific primers for FAM-labeled ER $\alpha$ and VIC-labeled $\beta$-actin were obtained from Applied Biosystem (Foster City, CA) and PCR condition for determination of ER $\alpha$ mRNA level was described previously [21]. Relative gene expression was determined using a previously described method [22].

\section{Plasmid construction and luciferase assay}

To make luciferase constructs containing 3' UTR of survivin, 3'UTR was amplified using a pair of primers whose sequences were 5'-gcTCTAGActgcctggtcccagagtg-3'and 5'-gcTCTAGAtaaaaccacatgagactttattgg-3'. PCR was performed with genomic DNA and digested using $\mathrm{Xba}$ I and ligated into pGL3-control vector (Promega Corporation, Madison, WI). The constructs were sequenced to ascertain the right orientation and authenticity in the vector. The 3' UTR of bcl-2 and cyclin D1 cloned into $\mathrm{Xba}$ I site of pGL-3 promoter were kindly provided by Dr. Ruggero De Maria (Mediterranean Institute of Oncology, Catania, Italy).

Cells were plated in a 96-well plate and grown to 80 $90 \%$ confluence. The firefly luciferase constructs (100 ng) were cotransfected with $40 \mathrm{nM}$ miRNA mimics into MCF-7 cells using lipofectamine 2000 reagent. To monitor transfection efficiency, cells were cotransfected with $10 \mathrm{ng}$ of the pRL-SV40 plasmid which encodes Renilla luciferase. Luminescence was measured $24 \mathrm{~h}$ after transfection using a dual-luciferase reporter assay system (Promega Corporation, Madison, WI). All transfections were performed in triplicate, and data were analyzed by normalizing firefly luciferase activity to Renilla luciferase activity for each sample. Each construct was tested in three independent transfections.

\section{MTS Cell proliferation assay}

MCF-7 cells were incubated in 5\% charcoal stripped FBS for $24 \mathrm{~h}$, then transfected with $40 \mathrm{nM}$ negative control or miR-143, miR-16 and miR-203 mimics. After $24 \mathrm{~h}$, cells were trypsinized into 96-well plates. Cells were treated with $10 \mathrm{nM} \mathrm{E}_{2}$ or ethanol (vehicle control) for 5 days, CellTiter 96 AQueous One Solution Cell Proliferation Assay (MTS) (Promega Corporation, Madison, WI) was performed to detect cell proliferation.

\section{Triple positive and negative breast cancer tissues}

Fourteen triple positive and 36 triple negative formalinfixed paraffin-embedded (FFPE) breast cancer tissue specimens were obtained from Bioserve Global Biorepository (Beltsville, MD). RNA was isolated from these FFPE tissue specimens using miRNeasy FFPE kit (Qiagen,
Valencia, CA) for detection of miR-16, miR-143 and miR-203 expression in triple positive and triple negative breast samples. MiR-631, a non-estradiol inducible miRNA was used as control. These studies were approved by the Institutional Review Board at University of Arkansas for Medical Sciences.

\section{Statistical analysis}

The differential analysis per miRNA expression was performed using a 2-sample (treated vs. control and triple positive vs. negative samples) Student's $t$-test. MicroRNAs expression was normalized with respect to RNU6B as an internal control. All statistical analyses were performed using the SAS software (version 9.1; SAS Institute, Inc., Cary, NC). A P value of less than 0.05 (2-sided) was considered to be statistically significant.

\section{Results}

Identification of estradiol induced cell proliferation and survival genes in MCF-7 cells

ER-positive MCF-7 cells have been extensively used as a model of hormone-dependent breast cancer. In response to $E_{2}$ stimulation, MCF-7 cells exhibit cell proliferation and growth response in an $\mathrm{E}_{2}$ dependent manner. Bcl-2, cyclin D1 and survivin have been shown to be implicated in the process of cell proliferation and survival. In previous studies, bcl-2 [7,23,24] and cyclin D1[9,10,25] mRNA levels have been found to be upregulated by $E_{2}$. Yet very few studies on the regulation of survivin by $E_{2}$ [12]. Consistently, we found that $\mathrm{E}_{2}$ significantly induced cyclin D1 expression at $6 \mathrm{~h}$ and $24 \mathrm{~h}$, it also dramatically enhanced bcl-2 and survivin expression at $24 \mathrm{~h}$ and $48 \mathrm{~h}$ (Figure 1). The upregulation of bcl-2, cyclin D1 and survivin induced by $E_{2}$ was in a time-dependent manner.

\section{Downregulation of a panel of miRNAs induced by $E_{2}$}

$E R \alpha$-mediated transcriptional regulation is one of the mechanisms of gene upregulation induced by $E_{2}$. MiRNAs have recently been shown to be another important post-transcriptional regulation of genes involved in cell growth and estradiol response in MCF-7 cells [18,26,27]. In order to explore whether miRNAs participate in the upregulation of bcl-2, cyclin D1 and survivin induced by $E_{2}$, we focused on the downregulated miRNAs that could play a role in the modulation of cell proliferation and survival genes at the post-transcriptional level. Based on previous miRNA array profilings $[18,20]$, QPCR was performed to examine the expression of miRNAs and it showed that miR-143, miR-16 and miR-203 were robustly repressed at 6,24 and $48 \mathrm{~h}$ upon $\mathrm{E}_{2}$ treatment (Figure 2) miR-631, a non-estradiol inducible miRNA, was used as a control in response to $E_{2}$ treatment.

$\mathrm{T} 47 \mathrm{D}$ is another estrogen responsive ER $\alpha$ positive breast cancer cell line which is used to examine the 


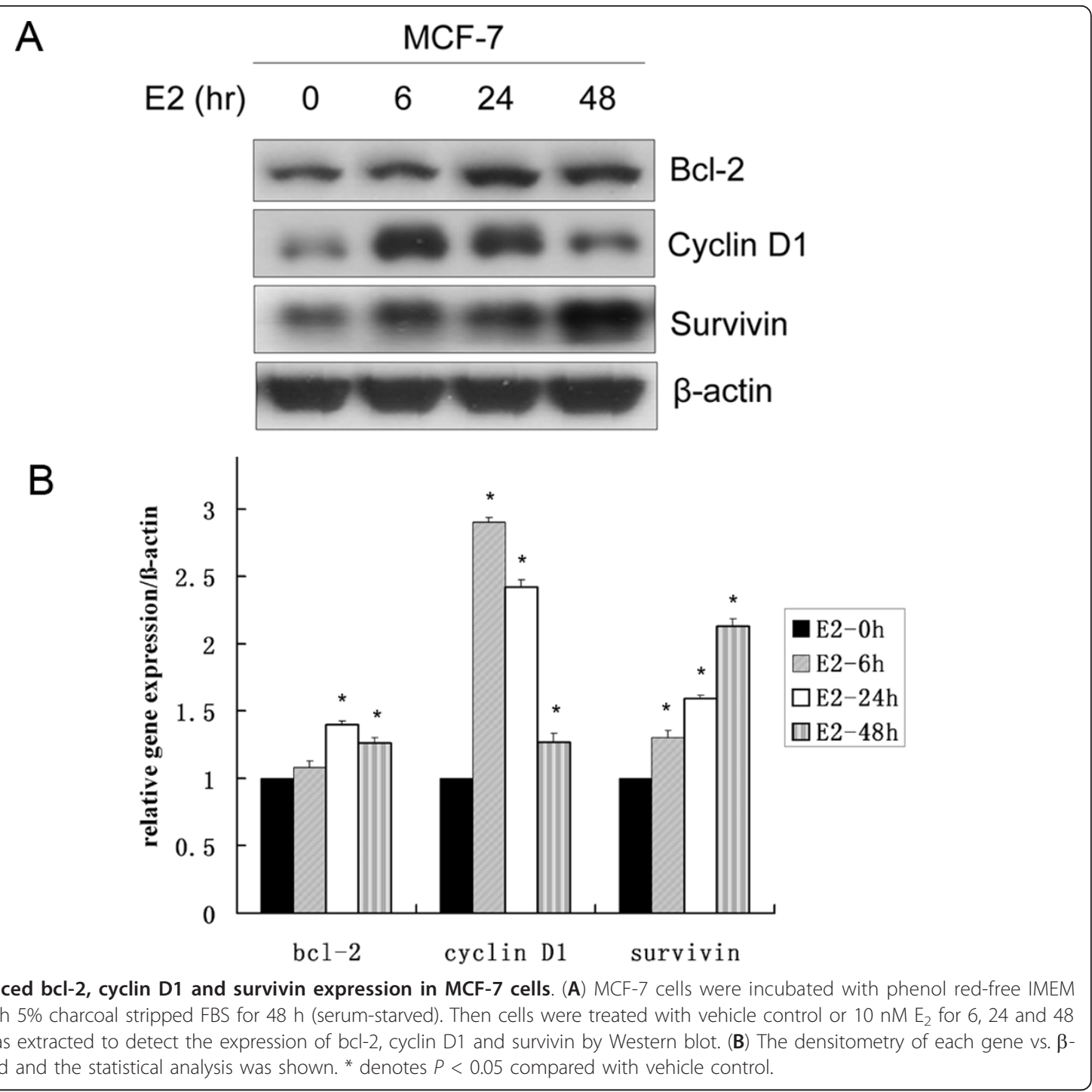

expression of bcl-2, cyclinD1 and survivin in response to $E_{2}$ treatment. Consistently, $E_{2}$ enhanced the expression of these genes but moderately reduced the expression of miR-16, miR-143 and miR-203 as shown in Additional file 1: Figure S1. Therefore, T47D cells displayed a similar effect in response to $E_{2}$ stimulation, although the effect was weaker than that of MCF-7 cells.

MiRNAs regulate bcl-2, cyclin D1 and survivin at the posttranscriptional level

$\mathrm{E}_{2}$ treatment leads to an increase in cell proliferation and survival genes bcl-2, cyclin D1 and survivin, it can also reduce the expression of several miRNAs. So we hypothesize that $E_{2}$ upregulates target genes associated with cell proliferation and survival by coordinately suppressing the expression of miR-143, miR-16 and miR203. It has been clearly demonstrated that miR-15 and miR-16 cluster targets bcl-2 and cyclin D1 [28,29] and
miR-143 targets bcl-2 [30]. Our results were in accordance with previous studies as shown in Figure $3 \mathrm{~A}$ and $3 B$. These miRNAs were able to significantly downregulate endogenous target genes bcl-2 and cyclin D1 expression at the protein level. QPCR was used to examine the level of the miRNAs and it indicated that transfection of miRNA mimics remarkably increased the level of miRNAs (Figure 3C). Furthermore, TargetScan and miRbase programs predict conserved binding sites of miR-16, miR-143 and miR-203 in the 3'-UTR of survivin. We further confirmed that these miRNAs target survivin at the post-transcriptional level by transfection of miRNA inhibitors and subsequent luciferase assay. It has been shown that transfection of miRNA inhibitors can potentially interfere with the expression of endogenous miRNAs and therefore enhance the expression of target gene survivin (Figure $3 \mathrm{D}$ and $3 \mathrm{E})$. 


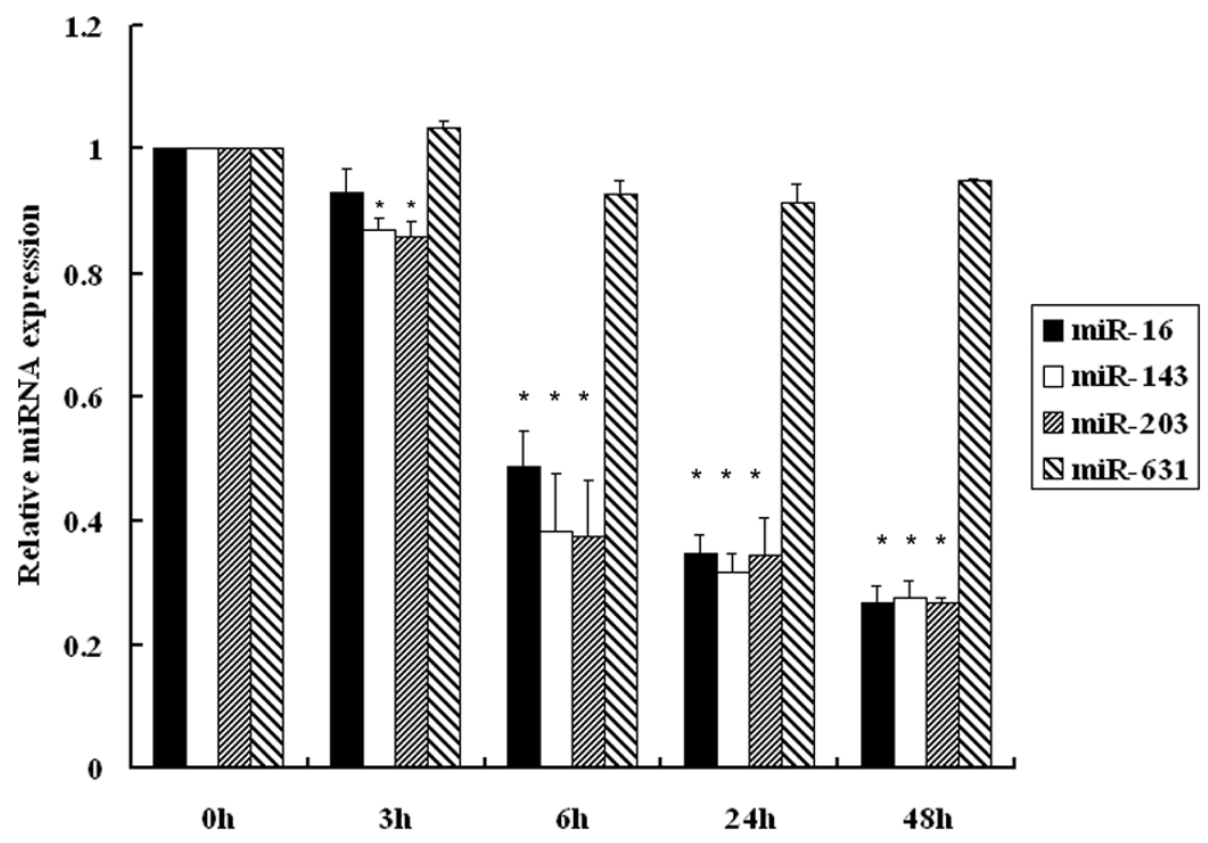

Figure $2 E_{2}$ reduced miR-16, miR-143 and miR-203 expression in MCF-7 cells. MCF-7 cells were treated as described in Figure 1 and stimulated by $E_{2}$ for $3,6,24$ and 48 h. Total RNA was extracted and miRNA expression levels were examined by QPCR. MiR-631 is a non- $E_{2}$ responsive miRNA serving as negative control. * denotes $P<0.05$ compared with vehicle control.

The biological activity of miRNAs is primarily mediated by interaction with binding sites in the 3'-UTR of target genes and translational inhibition. Finally, luciferase assay was performed to confirm the binding of the miRNAs to the 3'UTR of target genes. MCF-7 cells were co-transfected with miR-16, miR-143 or miR-203 mimics with bcl-2, cyclin D1, survivin 3'-UTR luciferase constructs containing the miRNAs binding sites respectively. As expected, miR-16 significantly suppressed the luciferase activity of bcl-2, cyclin D1, and survivin whereas miR-143 moderately inhibited luciferase activity of bcl-2 and survivin. Noticeably, miR-203 impaired luciferase activity of survivin. Therefore, the luciferase assay revealed that these miRNAs directly regulate the expression of the target genes bcl-2, cyclin D1, and survivin by binding to the 3'UTR of these genes (Figure $3 \mathrm{~F})$. Based on our previous results, it is likely that $\mathrm{E}_{2^{-}}$ mediated reduction in miRNAs expression resulted in lower amounts of miRNAs available to bind to their recognition sequences of bcl-2, cyclin D1 and survivin and thus increasing the luciferase activity of the reporter transcripts. This is possibly one mechanism of $E_{2}$ induced upregulation of genes involved in cell proliferation.

Regulation of miRNAs and the expression of target genes are ER $\alpha$-dependent

To investigate whether $\mathrm{E}_{2}$-mediated miRNA reduction and upregulation of target genes can be abrogated by anti-estrogens, we used ICI 182, 780 and raloxifene as antagonists of $E_{2}$. ICI 182, 780, a pure antiestrogen, is a competitive antagonist of $\mathrm{E}_{2}$ and blocks the transcriptional activation properties of ERs [31,32]. Raloxifene belongs to the family of selective estrogen receptor modulators (SERMs) that display agonistic or antagonistic activity in a tissue-dependent manner [33]. As we have shown, both ICI 182, 780 and raloxifene can attenuate the reduction of the miRNAs and consequently the induction of bcl-2, cyclin D1 and survivin expression by $\mathrm{E}_{2}$ (Figure $4 \mathrm{~A}, \mathrm{~B}$ ).

$\mathrm{E}_{2}$ binds predominantly to $\mathrm{ER} \alpha$ which leads to transcriptional regulation of genes involved in the control of cell growth and survival. To explore whether regulation of miRNA and the target genes is ER $\alpha$-dependent, siRNA was used to interfere with the expression of ER $\alpha$. It was found that knockdown of ER $\alpha$ remarkably impaired the induction of bcl-2, cyclin D1 and survivin by $\mathrm{E}_{2}$ (Figure $4 \mathrm{C}, \mathrm{D}$ ). In addition, $\mathrm{E}_{2}$-regulated cell proliferation and survival genes were examined in ER-negative MDA-MB-231 cells compared with those of MCF-7 cells. In contrast, $\mathrm{E}_{2}$ could not enhance bcl-2, cyclinD1 and survivin expression in MDA-MB-231 cells (Figure $4 \mathrm{E})$. Further studies on miRNA expression indicated that miR-16, miR-143 and miR-203 were not significantly affected by $\mathrm{E}_{2}$ in MDA-MB-231 cells (Figure $4 \mathrm{~F}$ ), indicating the potential modulation of cell growth and survival genes by miRNAs in reponse to $E_{2}$ was mediated by ER $\alpha$. 
A

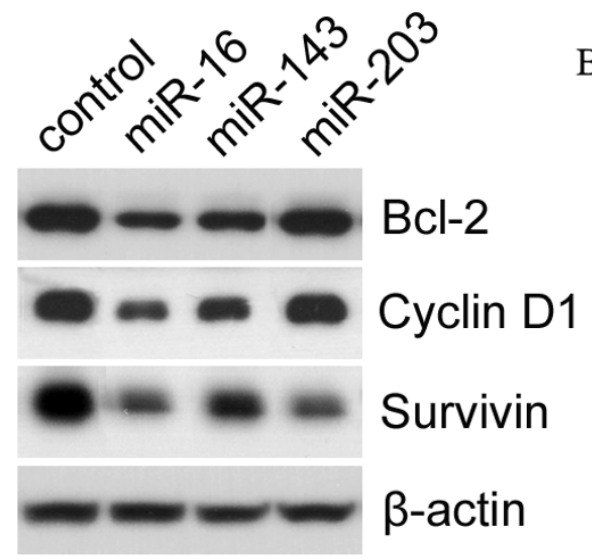

C

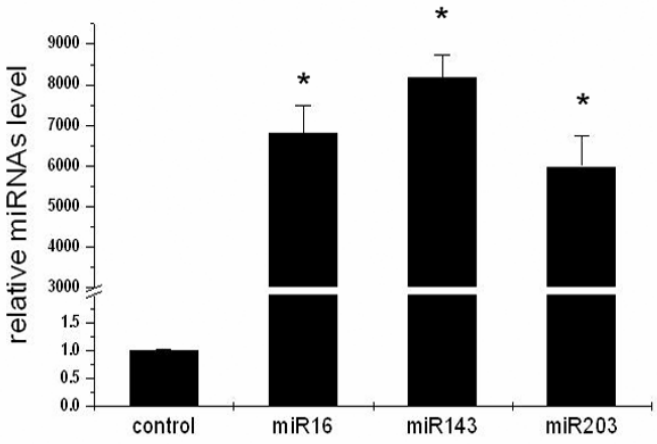

$\mathrm{E}$

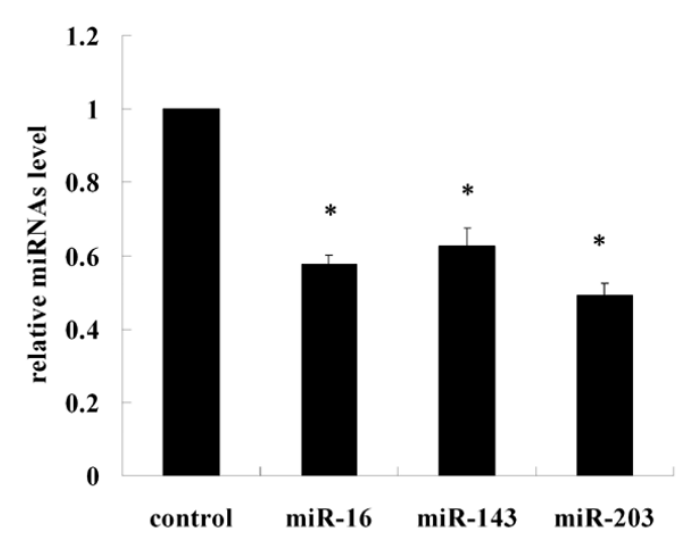

B

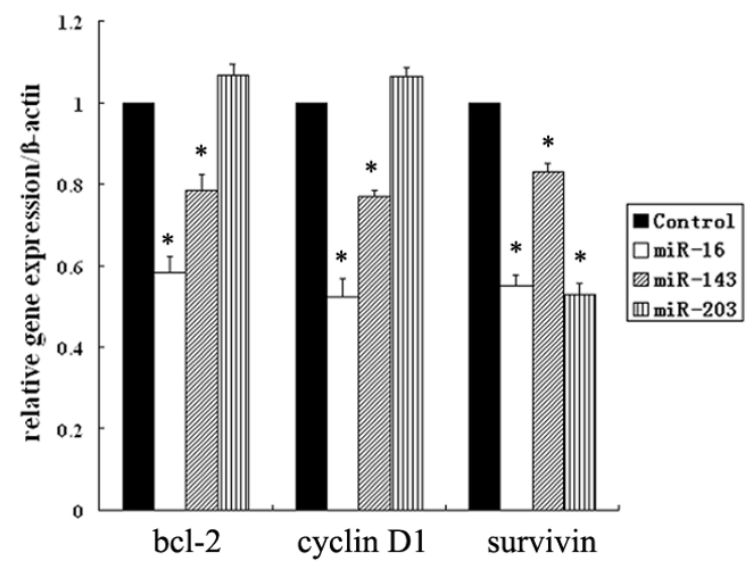

$\mathrm{D}$

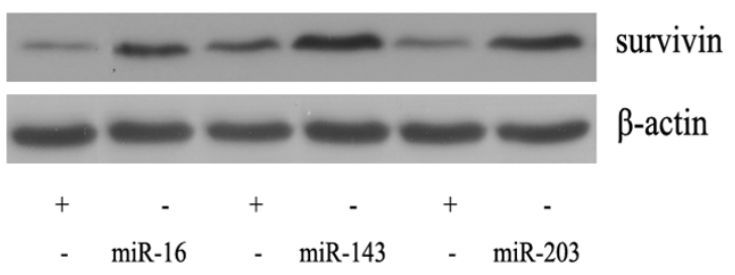

miRNA inhibitor $\quad-\operatorname{miR}-16 \quad-\operatorname{miR}-143 \quad-\operatorname{miR}-203$

Figure $3 \mathrm{E}_{2}$-responsive miRNAs downregulated endogenous bcl-2, cyclin D1 and survivin expression. (A) MCF-7 cells were transfected with 40 nM miR-16, miR-143 and miR-203 mimics for 48 h, Western blot was performed to detect endogenous bcl-2, cyclin D1 and survivin expression. (B) The densitometry of each gene vs. $\beta$-actin was indicated and statistically analyzed. * denotes $P<0.05$ compared with negative control miRNA. (C) RNA was extracted from MCF-7 transfected with miRNA mimics and RT-QPCR was performed to confirm the overexpression of these miRNAs. (D, E) MCF-7 cells were transfected with 40 nM miR-16, miR-143 and miR-203 inhibitors. After 48 h, Western blot was performed to examine endogenous survivin expression. Meanwhile, RT-QPCR was performed to examine the miRNAs expression. (F) MCF-7 cells were co-transfected with $40 \mathrm{nM}$ miR-16, miR-143 and miR-203 mimics together with $100 \mathrm{ng}$ bcl-2, cyclin D1 and survivin 3'UTR luciferase constructs and $10 \mathrm{ng}$ pRL-SV40. After $24 \mathrm{~h}$, luciferase activity assay was determined. * denotes $P<0.05$ compared with negative control. 
A

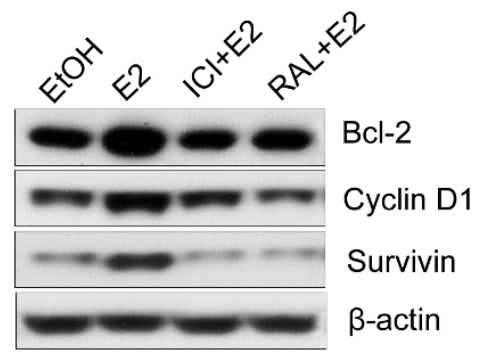

C

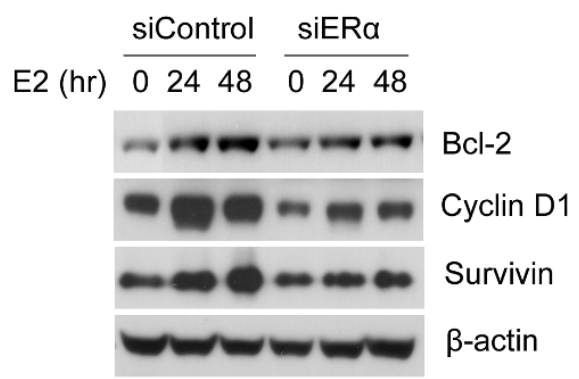

E

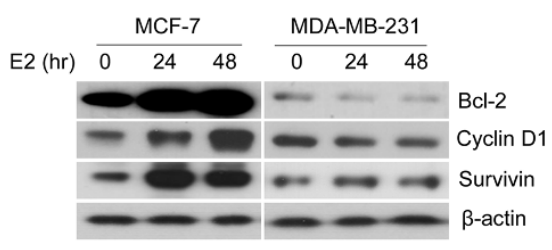

B

D

F
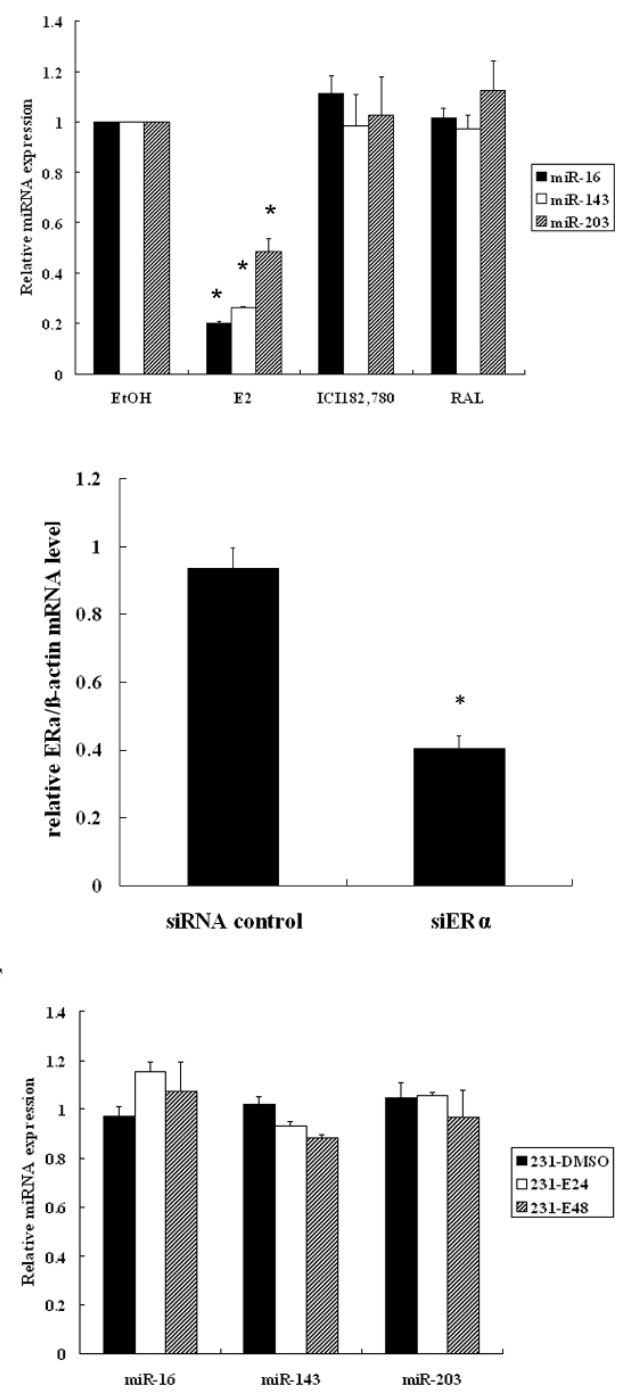

Figure 4 Regulation of miRNAs and the expression of target genes are ER $\alpha$-dependent. (A, B) MCF-7 cells were pretreated with $1 \mu \mathrm{M} I C \mid$ 182, 780 or Raloxifene for $6 \mathrm{~h}$, then treated with $10 \mathrm{nM} \mathrm{E}_{2}$ for $48 \mathrm{~h}$, protein was used for detection of bcl-2, cyclinD1 and survivin expression by Western blot. RNA was used to detect the expression of miRNAs by QPCR. * denotes $P<0.05$ compared with vehicle control (ethanol). (C, D) MCF-7 cells were transfected with $100 \mathrm{nM}$ ER $\alpha$ siRNA for $24 \mathrm{~h}$, then cells were treated with $10 \mathrm{nM} \mathrm{E}_{2}$ for $24 \mathrm{~h}$ and $48 \mathrm{~h}$. Western blot was used to detect the expression of bcl-2, cyclin D1 and survivin. QPCR was used to examine the level of ER $\alpha$ mRNA. (E, F) MDA-MB-231 cells were treated with $10 \mathrm{nM} \mathrm{E}_{2}$ for 24 and 48 h, miRNAs and target genes were examined. MCF-7 cells were used as ER-positive control.

MiR-16, miR-143 and miR-203 suppress $E_{2}$-dependent cell proliferation

$\mathrm{E}_{2}$ functions as a mitogen to stimulate cell proliferation and cell cycle transition. In response to $E_{2}$ treatment, miR-143, miR-16 and miR-203 were repressed and their target genes bcl-2, cyclinD1 and survivin were upregulated. We therefore investigated whether overexpression of miR-143, miR-16 and miR-203 interfered with $E_{2}$ induced cell proliferation in MCF-7 cells. The MTS assay showed that transfection of miR-143, miR-16 and miR-203 significantly inhibited $E_{2}$-induced cell proliferation (Figure 5A). Since miRNAs regulated bcl-2, cyclin D1 and survivin at the endogenous level as shown in
Figure 3A, we further explored whether transfection of these miRNAs impaired $E_{2}$-induced upregulation of bcl2 , cyclin D1 and survivin that control cell proliferation and cell cycle transition. As shown in Figure 5B and 5C, Western blot and densitometry were performed to determine the protein levels of these genes. In negative control miRNA group, $\mathrm{E}_{2}$ significantly induced upregulation of bcl-2, cyclin D1 and survivin compared with vehicle control. Figure 5D depicted the statistical analysis of the gene expression based on the results from Figure $5 \mathrm{C}$. The miRNAs significantly inhibited $\mathrm{E}_{2}$-induced cyclin D1 upregulation, in particular miR-16 inhibited $\mathrm{E}_{2}$ induced upregulation of cyclin D1 by $41 \%$ compared 


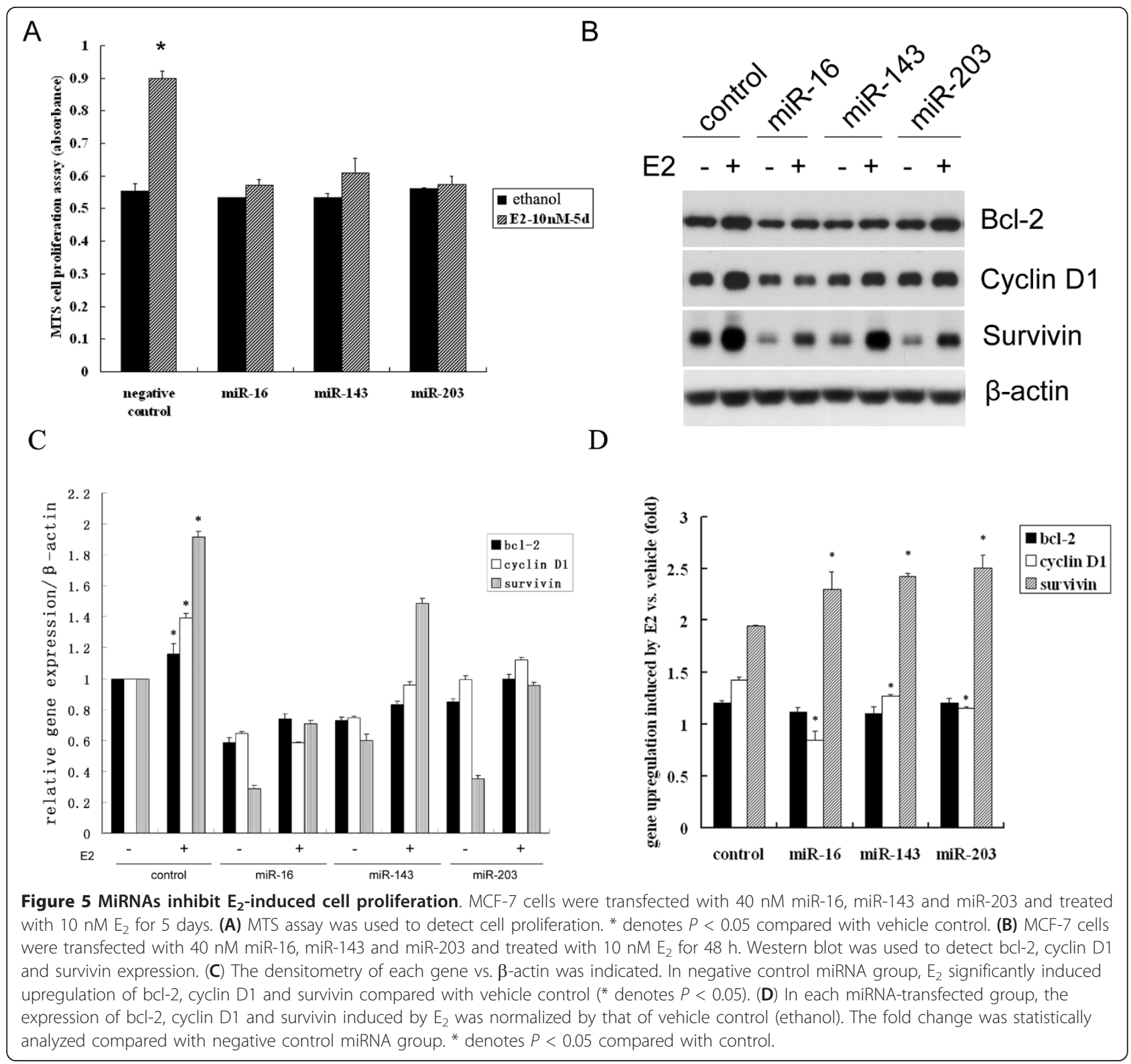

with negative control miRNA group. But the miRNAs have little inhibitory effects on $E_{2}$-induced bcl-2 and no inhibitory effects on $E_{2}$-induced survivin at all when compared with negative control miRNA group (Figure 5D). This probably was due to the robust interference of endogenous genes by the miRNAs in each group, which was in agreement with the result of Figure 3A. More importantly, these miRNAs impaired $E_{2}$-induced gene upregulation when compared with $\mathrm{E}_{2}$-induced negative control miRNA group. The data indicated that miR-143, miR-16 and miR-203 not only inhibited endogenous expression of bcl-2, cyclinD1 and survivin, but also disturbed $E_{2}$-induced upregulation of cyclin D1, an important cell cycle regulator, thereby, accounting for the impairment of cell proliferation.,

\section{MiR-16, miR-143 and miR-203 are highly expressed in ER positive breast tumors}

Triple-negative and triple positive breast cancers are defined by the status of estrogen receptor (ER), progesterone receptor (PR) and HER-2 expression. Because the triple-negative phenotype is more aggressive and not amenable to any form of endocrine therapy and has a high incidence of metastasis, the patients have a worse prognosis than patients with the triple positive phenotype [8]. Since miR-16, miR-143 and miR-203 target 
genes control cell proliferation and the miRNAs exhibit a growth suppressive effect in response to $E_{2}$, we speculated that these miRNAs may be differentially expressed in ER positive and negative breast tumors, acting as a potential causal link with tumor suppressive effects in breast cancer progression. Notably, as shown in Figure 6, miR-16, miR-143 and miR-203 were highly expressed in ER positive breast tumor, in contrast, miR-631 was not differentially expressed between ER positive and negative breast cancer, suggesting these anti-onco miRNAs may play an important role in breast cancer progression and response to chemotherapy.

\section{Discussion}

The discovery of miRNAs as a novel class of gene expression regulators has provided new strategies for disease diagnostics and therapeutics. Cell cycle, cell proliferation, cell survival and tumorigenesis are all regulated by miRNAs. Altered abundance of cell survival and cell cycle regulation proteins and aberrant expression of miRNAs frequently coexist in human breast cancers [34]. miRNAs are aberrantly expressed or mutated in cancer, acting as a novel class of oncogenes or tumor suppressor genes [35]. In this study, we demonstrated that a set of $E_{2}$-repressible microRNAs in breast cancer cell lines was associated with altered cell cycle progression and cell proliferation, which could play a causal role for miRNAs in controlling breast tumor growth.

In breast cancer, abnormalities of the cell cycle are frequently observed in response to $E_{2}$ treatment. Cyclin D1 encodes a key regulator of the cell cycle transition from $\mathrm{G} 1$ to $\mathrm{S}$ phase and is overexpressed in more than $50 \%$ of breast cancers, functioning as a rate-limiting factor for human breast cancer cell proliferation in vivo and in vitro [36,37]. The bcl-2 protein is associated with the inner mitochondrial membrane and functions to inhibit apoptosis and promote survival [38,39]. Survivin, a member of the inhibitor of apoptosis (IAP) family of antiapoptotic proteins, regulates the G1 checkpoint and G2/M phase of the cell cycle by associating with mitotic spindle microtubules. Survivin directly inhibits caspase-3 and caspase-7 activity, is inversely correlated with apoptosis and is positively correlated with cell proliferation $[40,41]$. We demonstrated that $E_{2}$ induced upregulation of cyclin D1, bcl-2 and survivin in MCF-7 cells, which played an important role in $\mathrm{E}_{2}$ stimulated cell proliferation and cell cycle transition. This result was consistent with previous studies [7,9,10,23-25]. Similar results were also observed in another estrogen-responsive breast cancer cells T47D, $\mathrm{E}_{2}$ dramatically induced the expression of cyclin D1, bcl-2 and survivin as shown in Additional file 1: Figure S1.

MiRNAs have emerged as a novel regulator of gene expression at the post-transcriptional level by base- pairing interactions between miRNAs and the 3'-UTR of their target mRNAs [16]. In order to explore whether miRNAs participate in the upregulation of bcl-2, cyclin D1 and survivin by $E_{2}$, we focused on the $E_{2}$-repressible miRNAs that may play a role in the modulation of cell proliferation and survival genes. Several studies have demonstrated that $E_{2}$ upregulates or downregulates a variety of miRNAs by miRNA expression profilings in MCF-7 cells [18-20]. The difference of the results may be due to the cell status, treatment and stimulation time. Based on previous studies, we demonstrated miR16, miR-143 and miR-203 were coordinately suppressed in response to $E_{2}$ treatment using QPCR quantification. Therefore, we proposed that these miRNAs might be involved in the regulation of cell proliferation and survival by targeting bcl-2, cyclin D1 and survivin at the post-transcriptional level.

Some publications have provided support for our hypothesis, Cimmino et al. [28] have demonstrated that $m i R-15 a$ and $m i R-16$ expression is inversely correlated with bcl-2 expression in Chronic lymphocytic leukemia and that both microRNAs negatively regulate bcl-2 at a post-transcriptional level. Bonci et al. [29] have demonstrated that the miR-15a-miR-16 cluster targets CCND1 (encoding cyclin D1), acting as tumor suppressor genes in prostate cancer by the control of cell survival, proliferation and invasion. miR-143 has been validated to target the oncogene KRAS [42] and may also modulate extracellular-regulated protein kinase 5 (ERK5) $[43,44]$ and bcl-2 [30]. In this study, we confirmed the previous studies that miR-16 targets bcl- 2 and cyclin D1 and miR-143 targets bcl-2. However, we can also see the impairment of endogenous cyclin D1 by miR-143 as shown in Figure 3A, which may result from the interference of ERK5 expression by miR-143 [30], since ERK5 has been shown to regulate cyclin D1[45,46]. TargetScan and miRbase programs predict conserved binding sites of miR-16, miR-143 and miR-203 in 3'-UTR of survivin. We further elucidated that miR-16, miR-143 and miR203 target survivin at the post-transcriptional level by transfection of miRNA mimics and inhibitors. Luciferase activity assay indicated these miRNA directly regulated the expression of survivin by binding to the 3'-UTR of survivin.

A miRNA regulates a variety of target genes, and a gene is modulated by many miRNAs. Therefore, in response to $E_{2}$ stimulation, several miRNAs are coordinately suppressed to upregulate the target genes which are involved in cell proliferation and survival. It provides a novel mechanism for regulation of genes containing ERE in the promoters. Previous studies have shown the ER $\alpha$-mediated transcriptional regulation of bcl-2, cyclin D1 mRNAs by binding to the ERE of target genes. We cannot conclude that the increase of bcl-2, cyclin D1 


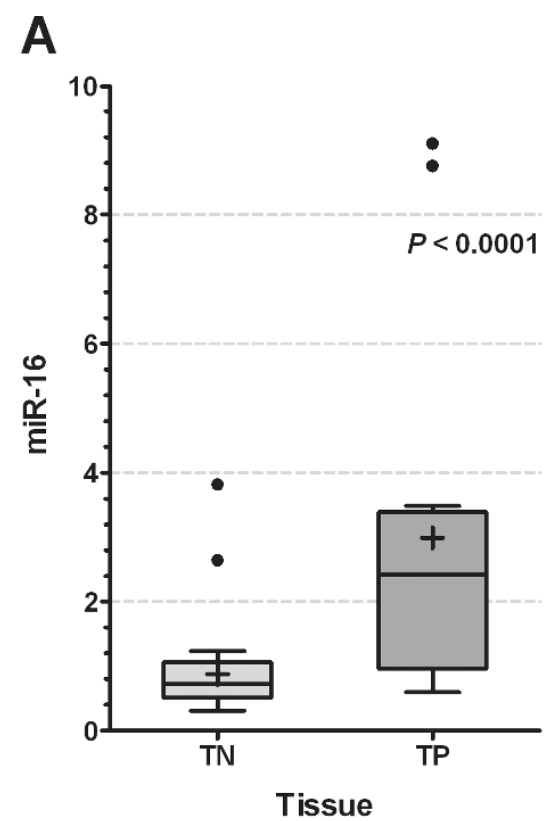

C

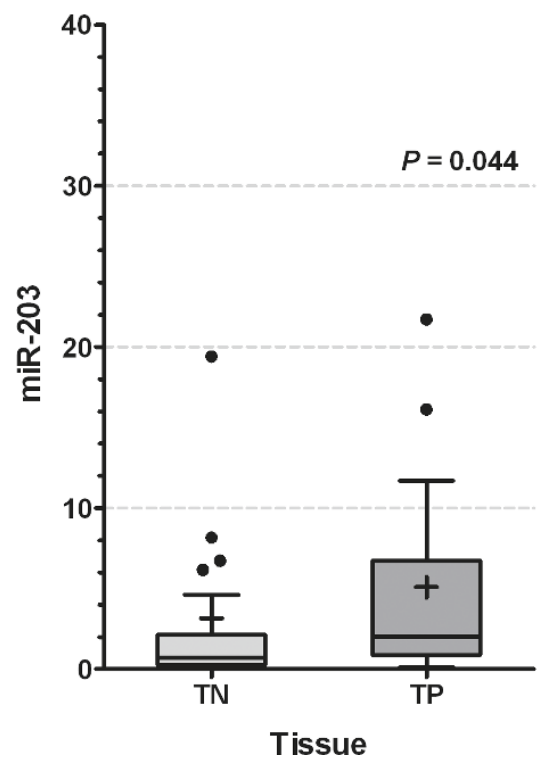

B

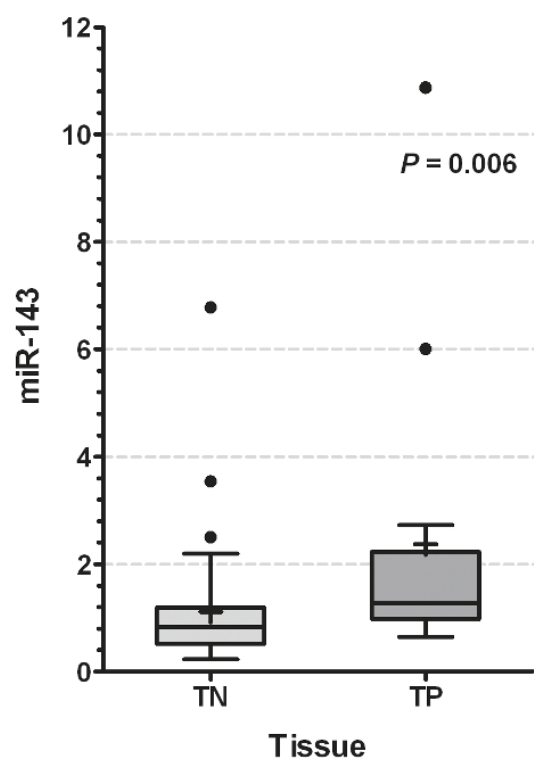

D

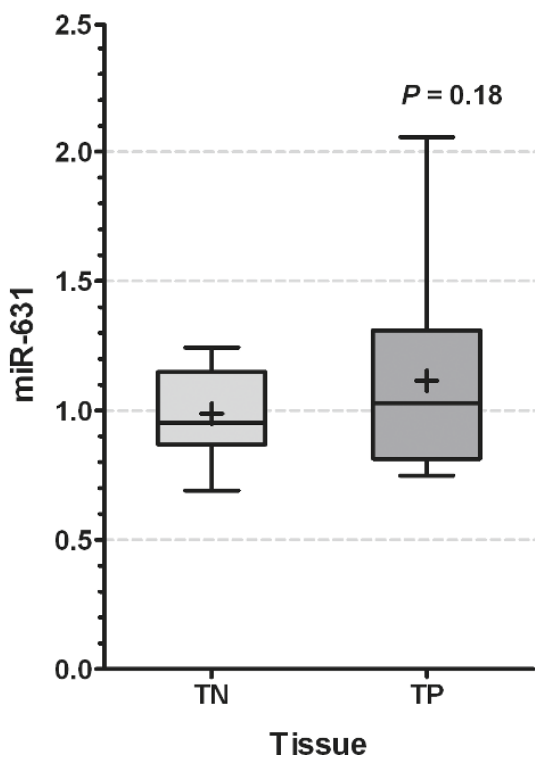

Figure 6 miRNAs were highly expressed in triple positive breast cancer tissues. (A-D) Total RNA was extracted from 14 triple negative and 36 triple positive breast cancer tissues to detect miRNAs expression by QPCR. MicroRNAs expression was normalized with respect to RNU6B as an internal control. T-test was used to indicate the difference. $P$ values are shown in the figures. TP denotes triple positive breast samples, TN means triple negative breast samples.

and survivin is due solely to $E_{2}$-mediated reduction of miR-16, miR-143 and miR-203, but miRNAs do play a crucial role in the post-transcriptional regulation because when actinomycin $\mathrm{D}$ was used to inhibit de novo RNA synthesis, $E_{2}$ can still enhance the expression of bcl-2, cyclinD1 and survivin, though at a low level (Additional file 2: Figure S2). Further studies will be needed to dissect the relative contributions of ER $\alpha$ mediated multiple pathways controlling bcl-2, cyclin D1 and survivin expression. 
$\mathrm{ER} \alpha$ is essential for $\mathrm{E}_{2}$-dependent growth, and its level of expression is a crucial determinant of response to endocrine therapy and prognosis in ER $\alpha$-positive breast cancer. Our data indicated that ICI 182, 780 and Raloxifene can abrogate $E_{2}$ repressed miRNA levels and therefore attenuate the expression of target genes. It is reported that ICI 182, 780 and Raloxifene can locally alter the ER $\alpha$ ligand binding structure via specific hydrophobic residues and decrease its transcriptional activity [47]. In addition, knockdown of the ER $\alpha$ protein also impaired $\mathrm{E}_{2}$ induced upregulation of bcl-2, cyclin D1 and survivin. In ER $\alpha$ negative MDA-MB-231 cells, $E_{2}$ has no effect on the regulation of miRNAs and target genes as shown in Figure 4E and 4F. In ER $\alpha$ negative non-cancer cells MCF-10A, we also observed similar effect (data not shown). Thus, the regulation is mainly dependent on ER $\alpha$ protein expression and transactivation in both breast cancer cells and in a normal breast cells.

Suzuki et al. [48] have recently shown that a central tumor suppressor, p53, enhances the post-transcriptional maturation of several miRNAs with growth-suppressive function, including miR-16, miR-143, miR-145 and miR-203 in response to DNA damage. P53 interacts with the Drosha processing complex through the association with the DEAD-box RNA helicase p68 and facilitates the processing of primary miRNAs to precursor miRNAs. In our study, we used MCF-7 cells carrying wild type p53 genes as a model to investigate the $\mathrm{E}_{2}$ repressible miRNAs target genes involved in cell proliferation. However, in p53 mutant ER $\alpha$-positive T47D cells, we observed similar regulation yet to a weaker extent. Previous studies have elucidated the interaction of ER $\alpha$ and p53 [49,50]. It is likely that both ER $\alpha$ and p53 participated in the regulation of $E_{2}$-repressible miRNAs. Further studies are needed to elucidate whether $\mathrm{ER} \alpha$-mediated induction of target genes by $\mathrm{E}_{2}$ via $\mathrm{p} 53$ regulated miRNA maturation.

The downregulated miRNA exhibits the growth suppressive effect in response to $E_{2}$. miR-16 and miR-15 act as tumor suppressors and control cell cycle transition by targeting cyclin D1 and cyclin E $[29,51]$. MiR-143 has been claimed to be a anti-oncomir in human colorectal tumors and can increase the sensitivity of chemotherapy [30,52-54]. MiR-203 has recently been identified to inhibit cell proliferation and invasion in prostate cancer, and reverse chemoresistance in p53-mutated colon cells [55-57]. In this study, overexpression of miR-16, miR143 and miR-203 remarkably inhibited $E_{2}$ induced cell proliferation of breast cancer cells. Further studies have shown that these miRNAs were significantly higher in triple positive than in triple negative breast tissues. This suggested a potentially tumor suppressive effect of the miRNAs on cancer progression of ER positive breast cancers, which may open new avenues for therapeutic intervention in breast cancer treatment.

\section{Conclusions}

It is our novel discovery that estradiol suppressed a panel of miRNAs, involving in the coordinated modulation of target genes that control cell proliferation and survival in breast cancer progression. Importantly, these miRNAs manifest tumor suppressive effects in response to estradiol stimulation and could possibly be biomarkers in triple positive breast tumors. In addition they may be potential biomarkers of breast cancer subtypes. Uncovering the critical role of these miRNAs in tumor suppression will contribute to the efficacy of breast cancer therapy.

\section{Acknowledgements}

We thank Ruggero De Maria (Mediterranean Institute of Oncology, Catania, Italy) for the generous gift of pGL3bcl-2 and pGL3-cyclinD1 plasmids. We thank Dr. Zhihua Liu (Chinese Academy of Medical Sciences) for the technical support. This work was supported by the funding of Susan G. Komen for the Cure BCTR0707584 and the National Natural Science Foundation (30973537).

\section{Additional material}

Additional file 1: Figure S1. $E_{2}$ induced the upregulation of bcl-2, cyclinD1 and survivin and moderately suppressed the level of the miRNAs in T47D cells. (A) T47D cells were incubated with phenol redfree IMEM supplemented with 5\% charcoal stripped FBS for $48 \mathrm{~h}$. Then cells were treated with vehicle control or $10 \mathrm{nM} \mathrm{E}$ for 24 and $48 \mathrm{~h}$, total protein was extracted to detect the expression of bcl-2, cyclin D1 and survivin by Western blot. (B) RNA was extracted from the cells and RTQPCR was used to examine the level of the miRNAs.

Additional file 2: Figure S2. $E_{2}$ induced upregulation of bcl-2, cyclin D1 and survivin at both transcriptional and the post-transcriptional level. (A) MCF-7 cells were pretreated or not with $2 \mu \mathrm{g} / \mathrm{ml}$ actinomycin $\mathrm{D}$ for $1 \mathrm{~h}$ and then stimulated with $10 \mathrm{nM} \mathrm{E}_{2}$ for $12 \mathrm{~h}$. Total protein was extracted to determine the expression of bcl-2, cyclin D1 and survivin. (B) The densitometry of each gene vs. $\beta$-actin was indicated and statistical analysis was shown. ${ }^{*}$ denotes $P<0.05$ compared with control (the first group).

\section{Abbreviations}

$\mathrm{E}_{2}$ : 17ß-estradiol; ER: Estrogen receptor; PR: Progesterone receptor; ERE: Estrogen response element; MiRNA: MicroRNA; QPCR: Real-time quantitative PCR; UTR: Untranslated region; DMEM: Dulbecco's modified eagle's medium; IMEM: Improved minimum essential medium; FBS: Fetal bovine serum; ECL: Enhanced chemiluminesence; FFPE: Formalin-fixed paraffin-embedded; SERM: Selective estrogen receptor modulators; MTS: 3-(4, 5-dimethylthiazol-2-yl)-5(3-carboxymethoxyphenyl)-2-(4-sulfophenyl)-2H-(tetrazolium).

\section{Author details}

'Department of Pharmacology, School of Chemical Biology \& Pharmaceutical Sciences, Capital Medical University, 100069, Beijing, China. ${ }^{2}$ Institute of Molecular Genetics, College of life science, Hebei United University, TangShan, 063000, China. ${ }^{3}$ Department of Medical Genetics, College of Medicine, University of Arkansas for Medical Sciences, Little Rock, 72205 USA. 


\section{Authors' contributions}

$X Y$ designed and performed the experiments, $X Y$ and $X Z$ drafted the manuscript. ID was responsible for data analyses. MB contributed to sample preparation. SK, MB and DL provided technical support and critically reviewed the manuscript. All authors read and approved the final manuscript.

\section{Competing interests}

The authors declare that they have no competing interests.

Received: 4 August 2011 Accepted: 20 January 2012

Published: 20 January 2012

\section{References}

1. Klinge CM: Estrogen regulation of microRNA expression. Curr Genomics 2009, 10(3):169-183.

2. Ali S, Coombes RC: Endocrine-responsive breast cancer and strategies for combating resistance. Nat Rev Cancer 2002, 2(2):101-112.

3. Carroll JS, Meyer CA, Song J, Li W, Geistlinger TR, Eeckhoute J, Brodsky AS, Keeton EK, Fertuck KC, Hall GF, et al: Genome-wide analysis of estrogen receptor binding sites. Nat Genet 2006, 38(11):1289-1297.

4. Kushner PJ, Agard DA, Greene GL, Scanlan TS, Shiau AK, Uht RM, Webb P: Estrogen receptor pathways to AP-1. J Steroid Biochem Mol Biol 2000, 74(5):311-317.

5. Safe S: Transcriptional activation of genes by 17 beta-estradiol through estrogen receptor-Sp1 interactions. Vitam Horm 2001, 62:231-252.

6. Shanmugam M, Krett NL, Maizels ET, Cutler RE Jr, Peters CA, Smith LM, O'Brien ML, Park-Sarge OK, Rosen ST, Hunzicker-Dunn M: Regulation of protein kinase $\mathrm{C}$ delta by estrogen in the MCF-7 human breast cancer cell line. Mol Cell Endocrinol 1999, 148(1-2):109-118.

7. Perillo B, Sasso A, Abbondanza C, Palumbo G: 17beta-estradiol inhibits apoptosis in MCF-7 cells, inducing bcl-2 expression via two estrogenresponsive elements present in the coding sequence. Mol Cell Biol 2000, 20(8):2890-2901

8. Bauer KR, Brown M, Cress RD, Parise CA, Caggiano V: Descriptive analysis of estrogen receptor (ER)-negative, progesterone receptor (PR)-negative, and HER2-negative invasive breast cancer, the so-called triple-negative phenotype: a population-based study from the California cancer Registry. Cancer 2007, 109(9):1721-1728.

9. Castro-Rivera E, Samudio I, Safe S: Estrogen regulation of cyclin D1 gene expression in ZR-75 breast cancer cells involves multiple enhancer elements. J Biol Chem 2001, 276(33):30853-30861.

10. Sabbah M, Courilleau D, Mester J, Redeuilh G: Estrogen induction of the cyclin D1 promoter: involvement of a cAMP response-like element. Proc Natl Acad Sci USA 1999, 96(20):11217-11222.

11. Cicatiello L, Addeo R, Sasso A, Altucci L, Petrizzi VB, Borgo R, Cancemi M, Caporali S, Caristi S, Scafoglio C, et al: Estrogens and progesterone promote persistent CCND1 gene activation during G1 by inducing transcriptional derepression via c-Jun/c-Fos/estrogen receptor (progesterone receptor) complex assembly to a distal regulatory element and recruitment of cyclin D1 to its own gene promoter. Mol Cell Biol 2004, 24(16):7260-7274.

12. Frasor J, Danes JM, Komm B, Chang KC, Lyttle CR, Katzenellenbogen BS: Profiling of estrogen up- and down-regulated gene expression in human breast cancer cells: insights into gene networks and pathways underlying estrogenic control of proliferation and cell phenotype. Endocrinology 2003, 144(10):4562-4574.

13. McKenna NJ, O'Malley BW: Minireview: nuclear receptor coactivators-an update. Endocrinology 2002, 143(7):2461-2465.

14. Glass CK, Rosenfeld MG: The coregulator exchange in transcriptional functions of nuclear receptors. Genes Dev 2000, 14(2):121-141.

15. Hammond SM: MicroRNAs as tumor suppressors. Nat Genet 2007, 39(5):582-583.

16. Lai EC: Micro RNAs are complementary to $3^{\prime}$ UTR sequence motifs that mediate negative post-transcriptional regulation. Nat Genet 2002, 30(4):363-364.

17. Bartel DP: MicroRNAs: target recognition and regulatory functions. Cell 2009, 136(2):215-233

18. Bhat-Nakshatri P, Wang G, Collins NR, Thomson MJ, Geistlinger TR, Carroll JS, Brown M, Hammond S, Srour EF, Liu Y, et al: Estradiol-regulated
microRNAs control estradiol response in breast cancer cells. Nucleic Acids Res 2009, 37(14):4850-4861.

19. Yamagata K, Fujiyama S, Ito S, Ueda T, Murata T, Naitou M, Takeyama K, Minami Y, O'Malley BW, Kato S: Maturation of microRNA is hormonally regulated by a nuclear receptor. Mol Cell 2009, 36(2):340-347.

20. Maillot G, Lacroix-Triki M, Pierredon S, Gratadou L, Schmidt S, Benes V, Roche H, Dalenc F, Auboeuf D, Millevoi S, et al: Widespread estrogendependent repression of micrornas involved in breast tumor cell growth. Cancer Res 2009, 69(21):8332-8340.

21. Yu X, Dhakal IB, Beggs M, Edavana VK, Williams S, Zhang X, Mercer K, Ning B, Lang NP, Kadlubar FF, et al: Functional genetic variants in the 3'untranslated region of sulfotransferase isoform 1A1 (SULT1A1) and their effect on enzymatic activity. Toxicol Sci 2010, 118(2):391-403.

22. Livak KJ, Schmittgen TD: Analysis of relative gene expression data using real-time quantitative PCR and the 2(-Delta Delta $C(T))$ method. Methods 2001, 25(4):402-408.

23. Wang TT, Phang JM: Effects of estrogen on apoptotic pathways in human breast cancer cell line MCF-7. Cancer Res 1995, 55(12):2487-2489.

24. Dong L, Wang W, Wang F, Stoner M, Reed JC, Harigai M, Samudio I, Kladde MP, Vyhlidal C, Safe S: Mechanisms of transcriptional activation of bcl-2 gene expression by 17 beta-estradiol in breast cancer cells. J Biol Chem 1999, 274(45):32099-32107.

25. Planas-Silva MD, Donaher JL, Weinberg RA: Functional activity of ectopically expressed estrogen receptor is not sufficient for estrogenmediated cyclin D1 expression. Cancer Res 1999, 59(19):4788-4792.

26. Wickramasinghe NS, Manavalan TT, Dougherty SM, Riggs KA, Li Y, Klinge CM: Estradiol downregulates miR-21 expression and increases miR-21 target gene expression in MCF-7 breast cancer cells. Nucleic Acids Res 2009, 37(8):2584-2595.

27. Castellano L, Giamas G, Jacob J, Coombes RC, Lucchesi W, Thiruchelvam P, Barton $G$, Jiao $L R$, Wait $R$, Waxman J, et al: The estrogen receptor-alphainduced microRNA signature regulates itself and its transcriptional response. Proc Natl Acad Sci USA 2009, 106(37):15732-15737.

28. Cimmino A, Calin GA, Fabbri M, lorio MV, Ferracin M, Shimizu M, Wojcik SE, Aqeilan Rl, Zupo S, Dono M, et al: miR-15 and miR-16 induce apoptosis by targeting BCL2. Proc Natl Acad Sci USA 2005, 102(39):13944-13949.

29. Bonci D, Coppola V, Musumeci M, Addario A, Giuffrida R, Memeo L, D'Urso L, Pagliuca A, Biffoni M, Labbaye C, et al: The miR-15a-miR-16-1 cluster controls prostate cancer by targeting multiple oncogenic activities. Nat Med 2008, 14(11):1271-1277.

30. Borralho PM, Kren BT, Castro RE, da Silva IB, Steer CJ, Rodrigues CM: MicroRNA-143 reduces viability and increases sensitivity to 5 -fluorouracil in HCT116 human colorectal cancer cells. FEBS J 2009, 276(22):6689-6700,

31. Robertson JF: Faslodex (ICI 182, 780), a novel estrogen receptor downregulator-future possibilities in breast cancer. J Steroid Biochem Mol Biol 2001, 79(1-5):209-212.

32. Wakeling AE, Dukes $M$, Bowler J: A potent specific pure antiestrogen with clinical potential. Cancer Res 1991, 51(15):3867-3873.

33. Fuchs-Young R, Glasebrook AL, Short LL, Draper MW, Rippy MK, Cole HW, Magee DE, Termine JD, Bryant HU: Raloxifene is a tissue-selective agonist/ antagonist that functions through the estrogen receptor. Ann N Y Acad Sci 1995, 761:355-360.

34. Yu Z, Baserga R, Chen L, Wang C, Lisanti MP, Pestell RG: microRNA, cell cycle, and human breast cancer. Am J Pathol 2010, 176(3):1058-1064.

35. Esquela-Kerscher A, Slack FJ: Oncomirs - microRNAs with a role in cancer. Nat Rev Cancer 2006, 6(4):259-269.

36. Fu M, Wang C, Li Z, Sakamaki T, Pestell RG: Minireview: Cyclin D1: normal and abnormal functions. Endocrinology 2004, 145(12):5439-5447.

37. Lee RJ, Albanese C, Fu M, D'Amico M, Lin B, Watanabe G, Haines GK, Siegel PM, Hung MC, Yarden Y, et al: Cyclin D1 is required for transformation by activated Neu and is induced through an E2Fdependent signaling pathway. Mol Cell Biol 2000, 20(2):672-683.

38. Hockenbery DM: The bcl-2 oncogene and apoptosis. Semin Immunol 1992 4(6):413-420

39. Korsmeyer $\mathrm{SJ}$ : $\mathrm{BCl}-2$ initiates a new category of oncogenes: regulators of cell death. Blood 1992, 80(4):879-886.

40. Zhang $\mathrm{R}$, Ma L, Zheng M, Ren J, Wang T, Meng Y, Zhao J, Jia L, Yao L, Han $H$, et al: Survivin knockdown by short hairpin RNA abrogates the growth of human hepatocellular carcinoma xenografts in nude mice. Cancer Gene Ther 2010, 17(4):275-288. 
41. Altieri DC: Survivin, versatile modulation of cell division and apoptosis in cancer. Oncogene 2003, 22(53):8581-8589.

42. Chen X, Guo X, Zhang H, Xiang Y, Chen J, Yin Y, Cai X, Wang K, Wang G, $B a Y$, et al: Role of miR-143 targeting KRAS in colorectal tumorigenesis. Oncogene 2009, 28(10):1385-1392.

43. Akao Y, Nakagawa Y, Naoe T: MicroRNAs 143 and 145 are possible common onco-microRNAs in human cancers. Oncol Rep 2006, 16(4):845-850.

44. Esau C, Kang X, Peralta E, Hanson E, Marcusson EG, Ravichandran LV, Sun Y, Koo S, Perera RJ, Jain R, et al: MicroRNA-143 regulates adipocyte differentiation. J Biol Chem 2004, 279(50):52361-52365.

45. Borralho PM, Simoes AE, Gomes SE, Lima RT, Carvalho T, Ferreira DM, Vasconcelos MH, Castro RE, Rodrigues CM: miR-143 overexpression impairs growth of human colon carcinoma xenografts in mice with induction of apoptosis and inhibition of proliferation. PLoS One 2011, 6(8):e23787.

46. Wang $X$, Tournier C: Regulation of cellular functions by the ERK5 signalling pathway. Cell Signal 2006, 18(6):753-760.

47. Lupien M, Jeyakumar M, Hebert E, Hilmi K, Cotnoir-White D, Loch C, Auger A, Dayan G, Pinard GA, Wurtz JM, et al: Raloxifene and ICI182, 780 increase estrogen receptor-alpha association with a nuclear compartment via overlapping sets of hydrophobic amino acids in activation function 2 helix 12. Mol Endocrinol 2007, 21(4):797-816.

48. Suzuki HI, Yamagata K, Sugimoto K, Iwamoto T, Kato S, Miyazono K: Modulation of microRNA processing by p53. Nature 2009, 460(7254):529-533.

49. Liu W, Ip MM, Podgorsak MB, Das GM: Disruption of estrogen receptor alpha-p53 interaction in breast tumors: a novel mechanism underlying the anti-tumor effect of radiation therapy. Breast Cancer Res Treat 2009, 115(1):43-50.

50. Menendez D, Inga A, Resnick MA: Estrogen receptor acting in cis enhances WT and mutant p53 transactivation at canonical and noncanonical p53 target sequences. Proc Natl Acad Sci USA 2010, 107(4):1500-1505.

51. Ofir M, Hacohen D, Ginsberg D: miR-15 and miR-16 Are direct transcriptional targets of E2F1 that limit E2F-induced proliferation by targeting cyclin E. Mol Cancer Res 2011, 9(4):440-447.

52. Akao Y, Nakagawa Y, Hirata I, lio A, Itoh T, Kojima K, Nakashima R, Kitade $Y$, Naoe T: Role of anti-oncomirs miR-143 and -145 in human colorectal tumors. Cancer Gene Ther 2010, 17(6):398-408.

53. Xu B, Niu X, Zhang X, Tao J, Wu D, Wang Z, Li P, Zhang W, Wu H, Feng N, et al: miR-143 decreases prostate cancer cells proliferation and migration and enhances their sensitivity to docetaxel through suppression of KRAS. Mol Cell Biochem 2011, 350(12):207-213.

54. Noguchi S, Mori T, Hoshino Y, Maruo K, Yamada N, Kitade Y, Naoe T, Akao Y: MicroRNA-143 functions as a tumor suppressor in human bladder cancer T24 cells. Cancer Lett 2011, 307(2):211-220.

55. Viticchie G, Lena AM, Latina A, Formosa A, Gregersen LH, Lund AH, Bernardini S, Mauriello A, Miano R, Spagnoli LG, et al: MiR-203 controls proliferation, migration and invasive potential of prostate cancer cell lines. Cell Cycle 2011, 10(7):1121-1131.

56. Saini S, Majid S, Yamamura S, Tabatabai ZL, Suh SO, Shahryari V, Chen Y, Deng G, Tanaka Y, Dahiya R: Regulatory role of miR-203 in prostate cancer progression and metastasis. Clin Cancer Res 2011, 17(16):5287-5298.

57. Li J, Chen Y, Zhao J, Kong F, Zhang Y: miR-203 reverses chemoresistance in p53-mutated colon cancer cells through downregulation of Akt2 expression. Cancer Lett 2011, 304(1):52-59.

\section{Pre-publication history}

The pre-publication history for this paper can be accessed here: http://www.biomedcentral.com/1471-2407/12/29/prepub

\section{doi:10.1186/1471-2407-12-29}

Cite this article as: Yu et al:: Induction of cell proliferation and survival genes by estradiol-repressed microRNAs in breast cancer cells. BMC Cancer 2012 12:29.

\section{Submit your next manuscript to BioMed Central and take full advantage of:}

- Convenient online submission

- Thorough peer review

- No space constraints or color figure charges

- Immediate publication on acceptance

- Inclusion in PubMed, CAS, Scopus and Google Scholar

- Research which is freely available for redistribution

Submit your manuscript at www.biomedcentral.com/submit
Biomed Central 